Int. J. Dev. Biol. 48: 913-924 (2004)

doi: $10.1387 / \mathrm{ijdb} .041875 \mathrm{kp}$

\title{
Genetic control of retinal specification and determination in Drosophila
}

\author{
KARTIK S. PAPPU ${ }^{1}$ and GRAEME MARDON* ${ }^{*}, 1,2,3,4,5$ \\ ${ }^{1}$ Program in Developmental Biology, ${ }^{2}$ Department of Pathology, ${ }^{3}$ Department of Molecular and Human Genetics, ${ }^{4}$ Department of \\ Ophthalmology and ${ }^{5}$ Department of Neuroscience, Baylor College of Medicine, One Baylor Plaza, Houston, TX, USA
}

\begin{abstract}
The Drosophila compound eye has long served as an outstanding model system to study many processes, including cell fate specification, cell division, cell growth and cell death. In addition, exploring the molecular basis of eye specification in Drosophila has identified a set of nuclear factors that trigger the conversion of a group of multipotent epithelial cells into eye primordia. These nuclear factors act in complex networks to regulate retinal specification and appear to be conserved throughout phylogeny. Finally, evidence suggests that these nuclear networks have been co-opted to specify cell fates in other tissues. We review the latest developments in the field of retinal specification in Drosophila and discuss several future directions that remain open for investigation.
\end{abstract}

KEY WORDS: Drosophila, retina, specification, determination, selector

\section{Regional specification in the eye-antennal imaginal disc}

With the exception of the proboscis, all external adult head structures in Drosophilaare derivatives of the eye-antennal imaginal disc (Haynie and Bryant, 1986). The larval eye-antennal disc is an epithelial monolayer that gives rise to the eye, antenna, ocelli, palpus and the surrounding head cuticle. The whole disc is derived from a group of approximately 20 cells that are set aside during embryonic development (Garcia-Bellido and Merriam, 1969). During the first two larval instar stages, cells of the eye disc divide and grow to give rise to the pool of progenitor cells that will comprise the adult head structures. The earliest indications of morphologically distinct eye and antennal fields in the disc appear in mid to late second instar larvae. The eye field gives rise to the eye proper, head cuticle, and the ocelli (Fig. 1). The antennal field gives rise to the antenna and head cuticle (Haynie and Bryant, 1986).

The development of the eye-antennal disc presents a unique challenge in that a ventral appendage, the antenna, and a dorsal appendage, the eye, have to be specified from an initially uniform epithelial field. Thus, separation of the eye and antennal fields is essentially a problem of compartmentalization. Compartments were originally defined as developmental units that share a common cellular lineage (Garcia-Bellido et al., 1973). These lineage restrictions are bestowed upon cells by selector genes, which provide molecular definitions of compartments. However, an altered view of selector gene function does not require lineage restrictions (Mann and Morata, 2000). This is especially true of the eye-antennal disc, which initially develops as a uniform field and is progressively refined into subunits with different fates. Early development of the eye and antennal fields are intimately linked and use common selector genes (Kenyon et al., 2003). Later, separation of the eye from the antenna requires distinct combinations of selector genes that function in one or the other domain. For the sake of brevity and clarity, we are concerned only with selection of the eye field in this review.

Drosophila eye development is a highly dynamic process that begins in the late second instar larva with the initiation of the morphogenetic furrow (MF) (Ready et al., 1976). The MF is a dorso-ventral indentation that appears at the posterior margin of the eye disc and traverses anteriorly, leaving in its wake differentiated photoreceptors, the light sensing neurons of the unit eye or ommatidium (Wolff and Ready, 1991). Each ommatidium is composed of eight photoreceptor neurons and eleven subsidiary cells, including cone, pigment, and bristle cells. The adult eye consists of 750-800 ommatidia arranged in a regular hexagonal array (Wolff and Ready, 1993). The MF coordinates many events that allow the transition from an undifferentiated epithelium to differentiated cell types. However, even before the initiation of the MF, many genetic events must be precisely orchestrated in order

Abbreviations used in this paper: egfr, epidermal growth factor receptor; HD, homeodomain; PD, paired domain; RD, retinal determination.

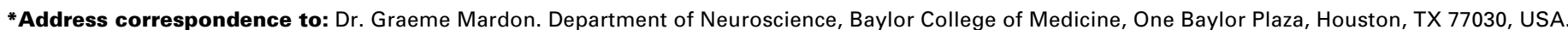
Fax: +1-713-798-3359. e-mail: gmardon@bcm.tmc.edu
} 
to create a fertile environment for later events that occur within and posterior to the furrow.

The development of the eye field itself can be broadly characterized as a three step process involving specification, determination, and differentiation. Specification and determination occur anterior to the morphogenetic furrow. Differentiation of specific cell types occurs posterior to the MF. Extensive research, beyond the scope of this review, has been dedicated to understanding events that occur posterior to the MF. In this review, we are concerned with specification and determination, the first two steps of eye development. Specification is defined as an early stage of commitment where the fate of a cell still depends upon environmental cues. Determination is a further stage of commitment where cell differentiation is autonomous, irreversible, and insensitive to environmental input. In this review, we define retinal specification and determination as progressive stages of development with an emphasis on the gene and protein expression states of the cells. The gene and protein expression profiles are used to define four Zones, of which Zone I and Zone II represent specified and determined cells, respectively. We discuss two broad classes of proteins that control specification and determination. First, distinct combinations of selector proteins are required for each step of eye development. Second, different extracellular inputs act in concert with selector complexes to allow the gradual transition of cells from specified to determined states.

\section{Selector genes which function during eye specification and determination}

We have identified four criteria that define an eye selector gene: 1) Loss-of-function mutations in these genes block early eye development; 2) Misexpression of eye selector genes can reprogram other imaginal discs to develop as retinal tissue; 3 ) Spatial and temporal domains of expression of these genes delimit the eye from the antennal field; 4) The encoded proteins are nuclear and in most cases DNA binding transcription factors that function in complexes, allowing combinatorial expression of

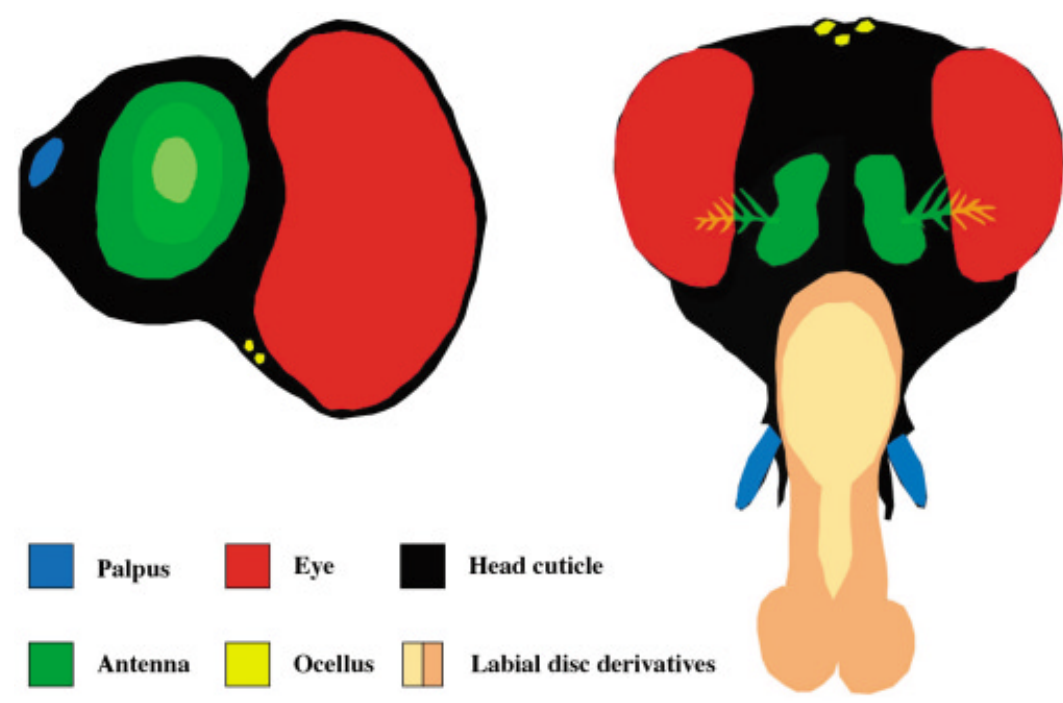

Fig. 1. A rough fate map of the eye-antennal disc (adapted and simplified from Haynie and Bryant, 1986). The eye-antennal disc gives rise to the eye, the antenna, the palpus and head cuticle. The rest of the head is derived from the labial discs. a limited number of factors to elicit multiple responses within eye disc sub-compartments. As will become apparent, these principles are not absolute and some genes that do not fulfill all four criteria can nevertheless be classified as eye selector genes.

\section{Loss-of-function phenotypes}

The earliest approach to understanding retinal specification in Drosophilainvolved phenotypic analysis of flies that develop with small or no eyes. Arguably the most significant among this class of flies is the eyeless (ey) mutant. The eymutation of Drosophila was first described in 1915 (Hoge, 1915) but it was not until 1994 that the gene mutated in eyelessflies was cloned and characterized (Quiring et al., 1994). Molecular analysis established Ey as a homolog of the vertebrate Pax 6 protein. Interestingly, mutations in the Pax6 gene cause the Small eye phenotype in mice and Aniridia in humans, suggesting for the first time that the genetic basis of retinal development shares similarities among divergent phylogenies (Glaser et al., 1992; Hill et al., 1991; Jordan et al., 1992). An ey paralog, twin of eyeless (toy), has also been identified in Drosophila (Czerny etal., 1999). Severe hypomorphs of toyand eyhave been described and these mutants develop into fully formed headless adults that fail to eclose from their pupal cases (pharate adults) (Kammermeier et al., 2001; Kronhamn et al., 2002). These results suggests that both genes are required for the proper development of all derivatives of the eye-antennal disc. Thus, both Pax6 orthologs fulfill the loss-of-function requirement to be classified them as "head selector" genes.

Four other genes, eyes absent (eya), sine oculis (so), dachshund (dac), and eyegone (eyg), have small or no eye mutant phenotypes (Bonini et al., 1993; Cheyette et al., 1994; Jang et al., 2003; Mardon et al., 1994). Clonal analysis suggests that eya or so mutant tissue fails to differentiate into photoreceptors and instead overproliferates giving rise to local overgrowth (Pignoni et al., 1997). In addition, eya and so are required for initiation and propagation of the MF and for proper differentiation of cells posterior to the furrow (Pignoni et al., 1997). Similarly, dacmutant clones encompassing the posterior margin of the eye disc fail to initiate photoreceptor differentiation (Mardon et al., 1994). In contrast, eygmutant clones are not recovered in third instar eye discs suggesting that eygis required to promote cell survival or proliferation (Jang et al., 2003). Severe hypomorphs of eygdevelop into pharate adults with no heads, a phenotype that is reminiscent of eyand toymutants (Jang et al., 2003). teashirt(tsh) mutant clones block dorsal eye development and result in increased cell proliferation in ventral regions of the eye disc. However, the reason for different dorsal and ventral phenotypes in tshmutant clones is still unclear (Singh et al., 2002). Thus, at least seven genes, toy, ey, eya, so, dac, eyg, and tsh, play important roles during eye development and fulfill the first requirement to be classified as eye selector genes. However, mutations in each of these genes do not exclusively effect eye development. For example, in addition to completely lacking eyes, dacnull mutants develop with truncated legs (Mardon et al., 1994). Therefore, the term "eye selector" should be interpreted to mean that a particular gene is required during eye development, but does not exclude functions for that gene in the 
development of other tissues. Although many other genes are also required for normal eye development in Drosophila, they fail to fulfill most or all of the other criteria characteristic of an eye selector gene and therefore are not listed here.

\section{Gain-of-function phenotypes}

Ectopic expression of ey in imaginal discs other than the eye disc leads to ectopic eye development, suggesting that the ey gene is sufficient to trigger the entire program of retinal differentiation (Halder etal., 1995). In addition, targeted expression of toyalso leads to ectopic eye development (Czerny et al., 1999). Since misexpression of these genes leads to the development of retinal tissue in all imaginal discs, they can be classified as eye selectors. Targeted expression of eya, dac, and eyg also results in ectopic eye tissue (Bonini et al., 1997; Jang et al., 2003; Shen and Mardon, 1997). However, the penetrance of such ectopic eyes is significantly lower than eyes induced by the misexpression of eyor toy. Since so does not induce ectopic retinal tissue upon misexpression, it fails one of the criteria to be classified as an eye selector gene. However, co-expression of so with eya has a strong synergistic effect, inducing ectopic eyes with much higher penetrance than those produced by eyaalone (Chen et al., 1999; Pignoni et al., 1997). In addition, eya and daccan synergize with each other to strongly induce ectopic eyes (Chen et al., 1997; Chen et al., 1999). These results suggest that combinations of certain eye selector genes are more potent at reprogramming the fates of heterologous tissue, lending credence to a combinatorial model of selector gene function in the eye.

Misexpression of at least two other genes, optix and teashirt (tsh), can induce ectopic eye development (Pan and Rubin, 1998; Seimiya and Gehring, 2000). However, loss-of-function mutations of optix have not been described, precluding an assessment of its role during normal eye development. In addition, mutant clones of two other genes, homothorax ( $h$ th) and extradenticle (exd), produce ectopic eyes in regions adjacent to the eye field that normally develop into head cuticle (Gonzalez-Crespo and Morata, 1995; Pai et al., 1998). This suggests that $h$ thand exdplay a repressive role during eye development. However, mutant clones of these genes in other tissues do not induce ectopic retinal development, suggesting that $h$ th and exd may delimit the borders of retinal tissue in the eye-antennal disc. In summary, at least ten genes (toy, ey, eya, so, dac, eyg, tsh, optix, hth, and exd) may be classified as eye selector genes based either on loss- or gain-offunction phenotypes.

\section{Expression of eye selector genes during normal development}

The expression patterns of the eye selector genes are highly informative and predictive of their potential function during normal eye development. In addition, analysis of the changes in expression of these genes in mutant backgrounds allows us to build a regulatory hierarchy in which these genes act.

ey and toy are expressed early in embryonic development in the eye primordia and continue to be expressed in the whole eye disc until the beginning of photoreceptor differentiation during the late second instar stage. Once photoreceptor differentiation begins, the expression of both ey and toy becomes restricted to the undifferentiated portion of the eye disc anterior to the MF (Czerny et al., 1999; Quiring et al., 1994). eyais first detectable in the eye field of the early second instar eye disc, while so, dac, and eygare

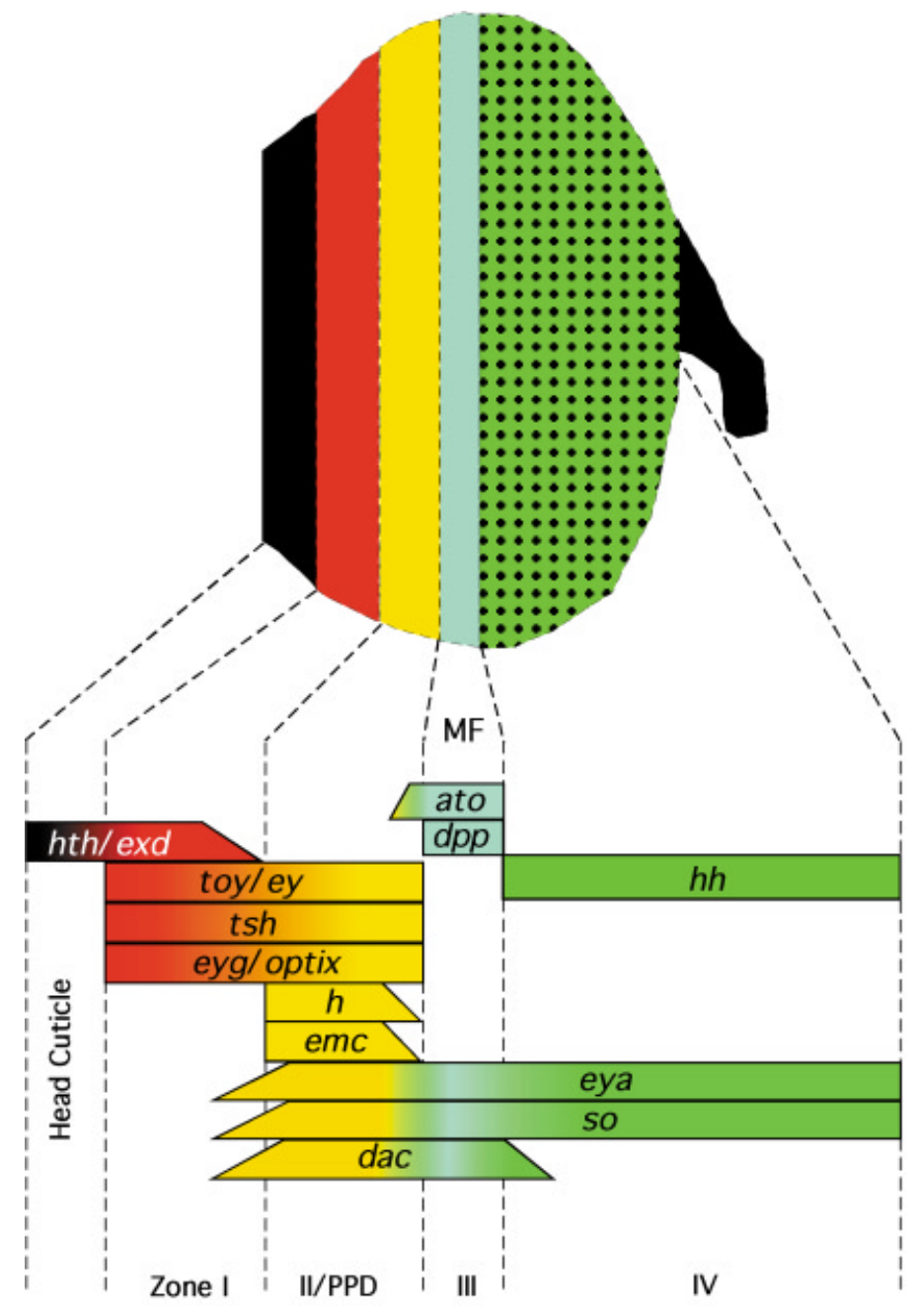

Fig. 2. Domains of selector gene expression in a third instar eye disc (see also Bessa et al., 2002). The upper panel is a drawing of a third instar eye disc, oriented with the anterior facing left and posterior facing right. Four zones marked by different colors are depicted in the eye field: Zone I, red; Zone II/PPD, yellow; Zone III, blue; and Zone IV, black and green, representing differentiated cell types. The head cuticle and the optic stalk are shown in black. The lower panel is a summary of gene expression patterns across these zones. Genes expressed exclusively in one zone are shown in corresponding colors. Genes expressed in more than one zone are shown with a gradient of colors. Note that genes in Zone IV are shown in green. See text for detailed description of the assignment of zones.

expressed at the posterior margin of late second instar eye discs (Bonini et al., 1993; Cheyette et al., 1994; Jang et al., 2003; Kenyon et al., 2003; Mardon et al., 1994). Once the MF initiates, these genes are expressed in slightly different patterns. A summary of the expression patterns of the eye selector genes in third instar larvae is depicted in Fig. 2. eya and so are expressed at high levels within and posterior to the MF. Anterior to the MF, eya and so are expressed in a gradient with decreasing expression near the antennal disc (Bonini et al., 1993; Cheyette et al., 1994). dac expression is highest immediately anterior to the MF but tapers sharply both anteriorly and posteriorly (Mardon et al., 1994). Once 
the MF initiates, eygand optxare expressed anteriorly in a pattern that closely mirrors ey and toy expression (Jang et al., 2003; Seimiya and Gehring, 2000). Both tsh and hth are expressed almost exclusively in anterior regions of first instar eye discs preceding the expression of other eye selector genes such as eya, so, and dac (Singh et al., 2002). In third instar eye discs, tsh is detectable anterior to the MF, overlapping the entire eydomain and the posterior portion of hth expression (Bessa et al., 2002). hth and exdare expressed in the most anterior regions of the eye disc that separate the eye and antennal fields.

\section{Selector gene expression patterns define developmental sub-domains in the eye field}

The expression patterns of the eye selector genes can be used to designate domains in the third instar eye disc that represent snapshots in developmental time (Fig. 2 and Bessa et al., 2002). The MF can be used as a molecular boundary between the anterior (undifferentiated) and posterior (differentiated) regions of the eye disc. Cells in Zone I express ey, toy, eyg, tsh, optx, hth, and exd. These cells are capable of becoming eye tissue, but remain undifferentiated due to the presence of $h$ th and exd. Cells in Zone II express eya, so, and dacin addition to ey, toy, eyg, tsh, and optx but do not express hth and exd. Cells of this zone are competent to express the proneural gene atonal (ato), which encodes a basic helix-loop-helix (bHLH) protein (Bessa et al., 2002; Greenwood and Struhl, 1999; Jarman etal., 1994). However, these cells also express hairy $(h)$ and extramacrochaetae (emc), negative regulators ato expression. $h$ encodes a basic HLH protein and emcencodes a HLH protein that lacks the basic DNAbinding domain. As a result only the most posterior cells of Zone Il express ato(Brown et al., 1991; Brown et al., 1995; Greenwood and Struhl, 1999; Van Doren etal., 1991). While hand emcare not required for photoreceptor differentiation, $h$ and emc double mutant cells that lie anterior to the MF result in premature ato expression, advancement of the MF, and premature photoreceptor differentiation (Brown et al., 1991; Brown et al., 1995). The term pre-proneural domain (PPD) was coined to describe Zone Il cells, since they express a group of HLH repressor proteins and are primed to express the proneural gene ato (Greenwood and Struhl, 1999). Cells in the MF express high levels of eya, so, and dacbut do not express ey, toy, eyg, tsh, optx, hth, and exdand comprise Zone III. Zone III cells also express ato in large clusters of cells anteriorly, which are progressively refined into single cells that will develop into the pioneer R8 photoreceptor. The posterior margin of Zone III is defined by the end of ato expression (Frankfort and Mardon, 2002). Zone IV cells lie posterior to the MF, rapidly downregulate dac expression, but continue to express eya and so. These zones of selector gene expression also delineate the boundaries between cells that are specified, determined, or differentiated. Thus, cells in Zone I are specified to become eye tissue, but remain in a proliferative state. Cells in Zone II/PPD are determined to become eye tissue and express a different set of selector genes. This view is experimentally supported by imaginal disc transplantation studies (Lebovitz and Ready, 1986). Therefore, the transition from specification to determination represents a change in competency, but both zones are restricted by expression of a set of repressive genes. Finally, cells in Zone III begin the program of differentiation by down-regulating expression of these repressive genes and activating the proneural gene ato. Genetic analyses of mutants of all the eye selector genes, coupled with their expression profiles, allow construction of a genetic hierarchy that includes most, but not all, of these genes.

\section{Genetic analysis and epistatic relationships}

Prior to initiation of the MF the entire eye disc is composed exclusively of Zone I and Zone II/PPD cells. The events that occur in Zone II guide the initiation and progression of the MF and have been subject to intense investigation. The Pax6homologs toyand ey lie at the top of a genetic hierarchy that we have termed the retinal determination (RD) network (Chen et al., 1999). The expression of toyand eyis unaffected in backgrounds mutant for all other eye genes. Furthermore, the expression of eyis reduced or lost in toy mutants, while toy expression is unaffected in ey mutants, suggesting that toyacts upstream of $e y$. This partial loss of ey in toymutants suggest that eyexpression is not under the exclusive control of toy (Kronhamn et al., 2002). However, misexpression of toyis unable to induce ectopic eye development in the absence of $e y$, suggesting that $e y$ is epistatic to toyduring eye development (Czerny etal., 1999). Expression of eya, so, and dacis lost in eymutant eye discs and expression of soand dacis lost in eya mutant eye discs (Halder et al., 1998; Pignoni et al., 1997). Expression of dac, but not eya, is lost in so mutant eyes (Pignoni et al., 1997). Finally, the expression of ey, eya, and sois not affected in dac mutant eye discs (Chen et al., 1997). Thus, loss-of-function analyses suggest that there is a linear genetic hierarchy that forms the core of the RD network: toy $\rightarrow e y \rightarrow e y a \rightarrow s o \rightarrow d a c$ (Fig. 3).

\section{Multiple feedback and cross regulatory interactions occur within the RD network}

If the linear genetic hierarchy describe above is true, then ectopic expression of genes that act high up in the network should induce the expression of downstream genes. Indeed, ectopic expression of toyinduces ey, while ectopic eyinduces expression of eya, so, and dac, placing toy and ey at the top of the RD network. ey misexpression in an eya mutant background is still able to induce so expression and an eye-specific enhancer of so can respond to ey, contains Pax6 binding sites, and is bound by Ey protein in vitro (Halder et al., 1998). Furthermore, versions of the so eye-specific enhancer that have mutated Ey binding sites are inactive in vivo(Niimi et al., 1999; Punzo et al., 2002). Taken together, these results suggest that Ey acts independently of eya to directly regulate soexpression. Similarly, ectopic expression of eycan induce eyaexpression in the absence of soor dacfunction (Halder et al., 1998). Although an eye-specific enhancer of eya is also induced in response to ectopic expression of $e y$, no consensus Pax 6 binding sites are contained in this enhancer, suggesting that eyregulation of eyamay be indirect (Bui et al., 2000; Zimmerman et al., 2000). Ectopic eyis unable to activate dacexpression in eya mutants, suggesting that induction of dacby eydepends on eya. Misexpression of eya, but not so, can induce the expression of dac, suggesting that eyaindeed acts between eyand dac (Chen et al., 1997; Chen et al., 1999). Contradicting this simple linear hierarchy, however, ectopic expression of either eya or dac can induce the expression of eyand ectopic daccan induce eya and so expression, These results suggest that extensive feedback regulation occurs during early retinal determination (Bonini et al., 1997; Shen and Mardon, 1997). Coupled with the ability of 
combinations of these genes to strongly synergize to produce ectopic eyes, we favor a model in which the RD genes act in a complex network to specify and determine eye fates. Thus, while a linear hierarchy is set in motion by the early expression of toy and $e y$, the end result is a complex network of feedback regulation that serves to "lock in" retinal fates in the eye disc.

\section{Some combinations of selector genes act independently of the core RD network}

Several other eye genes that act independently of, or in parallel to, ey have been identified but it is unclear if they act as integral members of the RD network. tsh misexpression in the eye disc induces $h$ th and suppresses eye development (Singh et al., 2002). Since $h$ thitself is a negative regulator of eye development, the effects of tshoverexpression are likely to be an indirect effect of $h$ thinduction. These results suggest that $t s h$ misexpression in the eye field is incompatible with photoreceptor differentiation. Clones of $h$ th overexpressing cells in Zone II/PPD, where it is not normally present, block the expression of $h$, eya, and dac, suggesting that these cells retain Zone I character. Consistent with this observation, clones coexpressing hth and tshanywhere in the eye field, retain ey expression and block eya and dac expression, suggesting that the Ey, Tsh, and $\mathrm{Hth}$ define a selector combination that prevents premature entry into Zone II/PPD state (Bessa et al., 2002). Paradoxically, misexpression of $t s h$ in the antennal disc can induce ectopic ey, eya, and dac expression, culminating in eye development (Pan and Rubin, 1998). This result is most likely due to the presence of the secreted signaling molecule Dpp in these regions, which recruits tsh and ey coexpressing cells of the antenna to adopt retinal fates (discussed in later sections).

Expression of eyg and optix is unaffected in eymutants while expression of tsh and hth in ey mutants has not been reported. The ability of eyg and optix to induce ectopic eyes is retained in ey $y^{2}$ mutants (Jang et al., 2003; Seimiya and Gehring, 2000). This result is surprising since all other genes that can induce ectopic eyes when misexpressed cannot do so in an eymutant background. In addition, ectopic expression of eyg and optix does not induce ey expression, suggesting that eyg and optix function independently of eyduring eye development. (Jang et al., 2003; Seimiya and Gehring, 2000). The results of these overexpression studies must be interpreted with caution, but could indicate a neomorphic effect. For example, it is possible that Ey and Eyg form heterodimers that regulate target gene expression during normal eye development. When the levels of either protein are reduced, eye development is impaired. However, if each protein is also capable of functioning as a homodimer, especially when overexpressed, then the heterodimer becomes dispensable for retinal specification. Such a scenario could explain why either ey or eyg is capable of ectopic eye induction in the absence of the other gene (Jang et al., 2003).

\section{Structure-function analyses of eye selector proteins}

Comparison of the amino acid sequences of the eye selector proteins among various species has uncovered conserved domains with important functional roles. In general, these domains confer DNA binding ability or are used for protein-protein interactions. However, some protein domains possess enzymatic or transactivation function.

\section{Toy, Ey, and Eyg are paired class homeodomain proteins}

Toy and Ey contain two important conserved domains, the homeodomain (HD) and the paired domain (PD). The PD is a bipartite DNA binding module containing PAI and RED motifs separated by a short linker (Xu et al., 1995). Each of these motifs contain helix turn helix $(\mathrm{HTH})$ features and are capable of DNA binding either alone or in combination. All HDs contain three $\alpha$ helical stretches, with helix 2 and helix 3 forming a characteristic $\mathrm{HTH}$ motif. While HDs can bind to DNA as monomers, paired class HDs can also dimerize and preferentially bind cooperatively to two palindromic TAAT half sites (Wilson et al., 1993). Eyg is also a paired class HD containing protein, but the PAI motif of the PD is truncated (Jang et al., 2003). Thus, the modified PD in Eyg may bind a different subset of DNA targets.

Surprisingly, a truncated form of the Ey protein that lacks the HD (Ey $\Delta H D)$ can rescue eye development in ey mutants, suggesting that the Ey HD is dispensable for eye development (Punzo et al., 2001). In addition, the Ey $\Delta \mathrm{HD}$ protein can activate known downstream genes such as so, suggesting that the PD is the functional DNA binding domain of Ey. In contrast, a truncated form of Ey that lacks the PD (Ey $\Delta \mathrm{PD})$ is ineffective in rescuing ey mutant eyes. However, Ey $\Delta$ PD can block appendage development and is able to suppress Distaless (DII) expression in the wing disc, suggesting that the HD contains repressive functions that have yet to be fully analyzed (Punzo et al., 2001).

\section{Ey, Tsh and Hth form a complex and promote proliferation of early eye disc cells}

$e y, t s h$, and $h$ th are normally coexpressed in first instar eye discs and are coexpressed in Zone I in third instar eye discs (Singh et al., 2002). In addition, Ey, Tsh, and Hth can form a complex and block expression of later acting transcription factors such as Eya and Dac (Bessa et al., 2002). Furthermore, coexpression of $e y, h t h$, and tshinduces proliferation of eye field cells and $h$ thmutant clones are rarely obtained anterior to the MF. These results suggest that the Ey, Tsh, and Hth complex is required for the survival or proliferation of anterior eye disc cells (Bessa et al., 2002). Tsh is a zinc finger transcription factor and $\mathrm{Hth}$ is a homeoprotein that complexes with, and is required for, nuclear localization of the homeoprotein Exd (Fasano et al., 1991; Pai etal., 1998; Rieckhof et al., 1997). Once the Hth-Exd complex moves to the nucleus it is recruited into a larger complex that includes Ey and Tsh. Clones mutant for hth or exdare sufficient to induce ectopic retinal development in regions that normally give rise to head cuticle, further suggesting that an $\mathrm{Ey}, \mathrm{Tsh}, \mathrm{Hth}$, and Exd containing complex prevents premature furrow initiation (Bessa et al., 2002).

\section{So and Optix are Six class homeoproteins}

Both So and Optix belong to the Six class of HD containing proteins, which contain a conserved Six domain in addition to the HD (Cheyette et al., 1994; Seimiya and Gehring, 2000). Based on phylogenetic comparisons of Six domain and HD amino acid sequences, the genes encoding Six class HD proteins are further classified into three subfamilies: Six 1/2, Six 3/6, and Six 4/5, (Kawakami etal., 2000). Drosophila sobelongs to the Six 1/2class and optixis a Six $3 / 6$ ortholog. An additional ortholog, D-Six4, has been identified in the Drosophila genome but loss- or gain-offunction mutations in this gene have not been described (Seo et 
al., 1999). The HD of Six proteins lacks two amino acids that are characteristic of most other HDs: an arginine at position 5 and a glutamine at position 12 of helix 1 . The arginine 5 residue makes important contacts in the TAAT core of the homeodomain target sequence. The absence of these two residues in the Six HD suggests that the DNA binding specificity of the Six class HDs is modified but analysis of So-DNA binding in Drosophila has been hampered by the lack of well defined downstream targets (Kawakami et al., 2000). Finally, the Six domain of So mediates formation of a complex with Eya and this interaction may drive the genetic synergy observed with these proteins in an ectopic eye induction assay (Pignoni et al., 1997).

\section{Eya is the prototypic member of a new class of protein tyrosine phosphatases}

The eyagene encodes a protein with a conserved C-terminal domain, termed the Eya domain 1 (ED1). The Eya protein also contains a smaller conserved domain, Eya domain 2 (ED2), which is embedded in a broader proline, serine, and threonine rich region (Bonini et al., 1993). Although Eya is a nuclear protein, it does not contain any easily recognizable DNA binding motif. Eya binds both So and Dac, suggesting that So provides a DNA binding function while Eya acts as a transactivator or adaptor protein to recruit other eye selectors such as Dac (Chen et al., 1997; Pignoni etal., 1997). However, a recent study has uncovered a putative phosphatase domain in Eya, suggesting that it has a potential enzymatic function (Rayapureddi et al., 2003; Tootle et al., 2003). Indeed, bacterially generated Eya proteins from many different species show varying degrees of tyrosine phosphatase activity in vitro. Moreover, Eya defines a new class of protein tyrosine phosphatases that use a nucleophilic aspartic acid in a metal-dependent reaction, which is in contrast to the cysteine nucleophile used by classical tyrosine phosphatases. Mutation of the nucleophilic aspartate to an aspargine $\left(\mathrm{Eya}^{\mathrm{D} 493 \mathrm{~N}}\right)$ in Drosophila Eya abolishes phosphatase activity in an in vitro assay and reduces the ability of this protein to rescue eye development in eya ${ }^{2}$ mutants. This suggests that the phosphatase activity of the Eya protein plays a role in eye development but is unlikely to be the only function of Eya, since the Eya ${ }^{\mathrm{D} 493 \mathrm{~N}}$ mutant protein still

TABLE 1

SUMMARY OF SELECTOR PROTEINS AND COMPLEXES THAT FUNCTION DURING DROSOPHILA RETINAL SPECIFICATION AND DETERMINATION

\begin{tabular}{llll} 
Gene & Domains Encoded & Predicted Function & Complexes With \\
\hline $\begin{array}{l}\text { twin-of-eyeless } \\
\text { eyeless }\end{array}$ & PD, HD & DNA binding & Not reported \\
eyes absent & PD, HD & DNA binding & Hth, Tsh \\
& ED1, ED2 & $\begin{array}{l}\text { Tyrosine phosphatase? } \\
\text { sine oculis }\end{array}$ & So, Dac \\
dachshund & SD, HD & DNA binding? & \\
eyegone & DD1, DD2 & DNA binding? & Eya \\
optix & PD, HD & DNA binding? & Eya \\
teashirt & SD, HD & DNA binding? & Not reported \\
homothorax & Zinc Finger & DNA binding? & Not reported \\
extradenticle & HD & DNA binding? & Ey, Hth \\
\hline
\end{tabular}

The "?" indicates assignment of predicted function based primarily on the presence of conserved domains and that direct downstream targets have not been reported. PD: Paired Domain; HD: Homeodomain; ED1: Eya Conserved Domain 1; ED2: Eya Conserved Domain 2; SD: Six Domain; DD1: Dachshund Domain 1; DD2: Dachshund partially rescues eya ${ }^{2}$ mutants (Rayapureddi et al., 2003). Furthermore, while presumed cellular targets of Eya phosphatase activity have yet to be determined, two likely candidates are So and Dac, proteins that function in the RD network and contain potential tyrosine phosphorylation sites.

\section{Eya is phosphorylated by MAP kinase and can function as a transactivator}

The Eya protein itself is a target for serine/threonine phosphorylation by epidermal growth factor receptor-mediated MAP kinase activity. This phosphorylation of Eya increases ectopic eye induction in a misexpression assay. Conversely, mutations that destroy the MAPK phosphorylation sites reduce Eya activity (Hsiao etal., 2001). Thus, Eya phosphorylation may act as a switch to modulate the activity of Eya. An N-terminal conserved domain in Eya, ED2, functions as a transactivator in S2 cell culture assays (Silver et al., 2003). The two known MAP kinase phosphorylation sites are embedded within ED2, suggesting that phosphorylation could modify the ability of Eya to function as a transactivator. In addition, Eya can bind to itself in an S2 cell two-hybrid assay, suggesting that homotypic Eya interactions may be important for Eya function in vivo (Silver et al., 2003). Coupled with the ability to complex with So, these results suggest that Eya may provide transactivation function to the DNA binding partner So. Further analysis of the functional significance of an Eya-So complex awaits identification of downstream targets of these proteins.

\section{Dac is a Winged-Helix DNA binding protein}

Like Eya, Dac was characterized initially as a novel nuclear protein. Interspecies comparisons of Dac protein show two conserved domains: An N-terminal dachshund domain 1 (DD1, also called Dachbox-N) and a C-terminal dachshund domain 2 (DD2, also called Dachbox-C) (Davis et al., 1999; Kozmik et al., 1999). DD1 is weakly similar to a domain in the Ski/SnoN protooncoproteins that is required for cellular transformation and transcriptional regulation. The crystal structure of the highly conserved, 107 amino acid DD1 of human Dach1 reveals a DNA binding region that is similar to the winged helix/forkhead $(\mathrm{HFH})$ family of DNA binding transcription factors (Kim et al., 2002). Since DD1 shares $78 \%$ identity among various species, Drosophila Dac also very likely functions as a DNA binding transcription factor (Kim et al., 2002). However, direct tests of the function of DD1 await identification of downstream targets of Dac. In addition to its putative DNA binding activity, Dac binds to, and synergizes with, Eya via DD2 to induce ectopic eye development (Chen etal., 1997). More recent studies have revealed, however, that a truncated version of Dac that lacks DD2 (Dac- $\Delta$ DD2), but not DD1, can rescue eye development in dacmutant flies, suggesting that DD2 is largely dispensable for normal eye development (Tavsanli and Mardon, 2004). However, dac missense mutants that encode a protein that is truncated in DD2, display moderate phenotypes. Therefore, it appears that this requirement for DD2 to modulate endogenous Dac function is circumvented by overexpression of Dac- $\Delta$ DD2. Moreover, Dac- $\Delta \mathrm{DD} 2$ is as efficient as full length Dac protein in its ability to synergize with Eya in an ectopic eye induction assay. These results suggest that the presence of DD1 is sufficient for most of Dac function in vivo, and that Dac-Eya synergy may not be mediated by a physical interaction of these two proteins. 
Selector protein combinations define progressively distinct zones in the eye field

In general, Ey, Eya, So, Dac, Tsh, Hth, and Exd are all nuclear proteins that function as parts of larger complexes that include at least one DNA binding protein (Table 1). Therefore, these proteins satisfy important criteria for being classified as eye selector proteins. The roles of other proteins in the eye, such as Eyg and Optix, are less clear and require further investigation. The subdivision of the eye field into four broad zones is based on gene or protein expression and the function of the distinct protein complexes that are formed in these zones (Fig. 2 and Table 1). Moreover, progressive induction and repression of eye selector genes may create specialized protein complexes which define distinct domains with progressively increased capacity to differentiate as photoreceptor cells.

\section{Integration of extracellular signals with eye selector complexes}

Secreted growth and patterning molecules are used reiteratively during development to define compartment boundaries and to sustain cell growth and division. Cells receiving extracellular signals combine these inputs with their complement of selector complexes to mediate the expression of downstream targets required for specification, determination, and eventually differentiation. This permits multiple cell and tissue types to be generated by a limited number of growth factors acting in concert with field specific selectors. Moreover, many growth factors behave as morphogens to pattern tissues during development (Freeman and Gurdon, 2002; Neumann and Cohen, 1997). Two criteria are often used to classify a molecule as a morphogen. First, the molecule must function in a non-cell autonomous fashion, influencing the fates of cells outside of its expression domain. Second, morphogens assign different positional values to cells in a concentration-dependent manner. As with the criteria for classification as a selector protein, the rules that define a morphogen are not absolute.

The dynamic nature of eye disc development makes it difficult to define compartments with fixed boundaries. In theory, the position of the MF could define a boundary between anterior and posterior compartments. However, since the MF traverses the entire eye disc from posterior to anterior, there is no fixed compartmentalization of the eye disc along this axis. Therefore, in the eye disc, it is useful to think of the area of influence of a diffusible signaling molecule as a moving domain of potential cell recruitment. The concentration-dependent effects of diffusible molecules in this context may be primarily to enable a group of cells to make a gradual transition from one selector zone to another. Cells anterior to the MF are regularly dividing, while cells near the MF are exposed to extracellular signals emerging from the MF. In response these cells stop dividing, begin differentiation, and emerge posterior to the MF, driving a new wave of recruitment.

At least five different extracellular inputs are used during specification of cell fates in the Drosophila eye. The genes hedgehog $(h h)$ and decapentaplegic (dpp) encode proteins that act as positive regulators of eye development (Heberlein et al., 1995; Heberlein et al., 1993). The genes Delta (DX and spitz (spi) encode the ligands for Notch $(M)$ and the epidermal growth factor receptor (egfi), respectively, and these signaling pathways are also essential for normal eye development (Freeman, 1994; Tio et al., 1994; Tio and Moses, 1997). Another gene, wingless (wg), encodes a protein that acts as a negative regulator of differentiation, ensuring that photoreceptor morphogenesis occurs in an ordered posterior to anterior progression. While much is known about the phenotypic outcomes of loss- and gain-of-function of individual signaling pathways in the eye, the precise interactions of the intracellular transducers of signaling with selector complexes remain the focus of many investigative efforts.

\section{Hedgehog and Decapentaplegic are required to initiate photoreceptor morphogenesis}

Both $\mathrm{Hh}$ and Dpp are required for normal development of all imaginal discs (Lee etal., 1992; Spencer etal., 1982). Furthermore, mutations in either hhor dpp block MF initiation (Dominguez and Hafen, 1997; Heberlein et al., 1993; Ma et al., 1993). In addition, loss-of-function clones of smoothened (smo) or thick veins (tkv) or punt (punt), which encode receptors for Hh and Dpp (type I and type II) respectively, block initiation of the MF (Burke and Basler, 1996; Curtiss and Mlodzik, 2000; Hazelett et al., 1998; Pappu et al., 2003; Strutt and Mlodzik, 1997). Similarly, loss-of-function clones of mothers against decapentaplegic (mad), the intracellular transducer of $d p p$ signaling, also block MF initiation (Curtiss and Mlodzik, 2000; Wiersdorff et al., 1996). Misexpression of hh or $d p p$ in cells anterior to the endogenous MF can initiate ectopic MFs in the eye disc (Heberlein et al., 1995; Pignoni and Zipursky, 1997). Occasionally, ectopic expression of $d p p$ in the anteriormost regions of the eye disc results in a complete duplication of the eye disc and ectopic expression of $h$ hcauses large overgrowth of eye tissue (Chanut and Heberlein, 1997; Pignoni and Zipursky, 1997). However, the ability of $h$ hor $d p p$ to induce ectopic MFs is limited exclusively to the eye field. Similarly, clones mutant for patched (ptc) or protein kinase $A$ ( $p k a)$, which encode negative regulators of $\mathrm{Hh}$ signaling, result in inappropriate activation of the Hh pathway and induce precocious MFs and ectopic photoreceptor differentiation anterior to the normal MF (Dominguez and Hafen, 1997; Ma and Moses, 1995; Pan and Rubin, 1995; Strutt and Mlodzik, 1995). These results suggest that $\mathrm{Hh}$ and Dpp are each necessary and sufficient to initiate the MF and consequent photoreceptor differentiation within the eye field. Interestingly, it appears that these signaling pathways function redundantly during MF progression.

\section{Hedgehog functions to activate both dpp and Eya during MF initiation}

The earliest expression of both $h$ hand $d p p$ precedes initiation of the MF. Immediately prior to the initiation of MF, hhand $d p p$ are expressed at the posterior margin of the eye disc, and expression of $d p p$ is dependent on $h h$ throughout eye disc development. Once the MF initiates, dppexpression is restricted to the MF while $h h$ is expressed in all cells posterior to the MF (Borod and Heberlein, 1998; Masucci et al., 1990; Royet and Finkelstein, 1997). The progressive expression of $\mathrm{Hh}$ and Dpp from Zone IV to Zone III is thought to drive the furrow anteriorly, leaving differentiated photoreceptors in its wake. These results suggest that the primary, and potentially only, role of $h h$ signaling in the eye disc is to activate the expression of $d p p$ in the MF. However, two new reports further clarify the mechanism of $\mathrm{Hh}$ signaling in the eye disc (Fu and Baker, 2003; Pappu etal., 2003). smomutant 
clones that encompass the posterior margin of the eye disc do not initiate Eya expression or photoreceptor differentiation, suggesting that eya may also be target of $h$ hsignaling in the eye. Consistent with this hypothesis, photoreceptor differentiation in posterior margin smo mutant clones can be rescued by a combination of $d p p$ and eya, but not either gene alone (Pappu et al., 2003). Moreover, the primary effect of $\mathrm{Hh}$ signaling is to relieve repression of eya by the repressor form of Cubitus interruptus ( $\left.\mathrm{Ci}^{\text {rep }}\right)$, the intracellular transducer of $h$ hsignaling. Surprisingly, the activator form of $\mathrm{Ci}\left(\mathrm{Ciact}^{\mathrm{a}}\right)$, is largely dispensable for normal eye development (Fu and Baker, 2003; Pappu et al., 2003). This lack of function for $\mathrm{Ci}^{\mathrm{act}}$ is contrary to the mode of action of $h$ in other imaginal tissues, where $h$ h signaling is required not only to block the production of $\mathrm{Cirep}$, but also to stabilize full length $\mathrm{Ciact}^{\text {, }}$, which can then activate target genes (Methot and Basler, 1999).

\section{Hh and Dpp mediate a two step transition from Zone I(specified) to Zone II (determined) and Zone III (differentiated) states}

The expression of eya, so, and dac is highly reduced or completely blocked in $d p p$ mutant eye discs (Chen et al., 1999). Moreover, posterior margin clones of either smo or mad do not express Eya or Dac (Curtiss and Mlodzik, 2000; Pappu et al., 2003). In addition, mad mutant clones that lie at the posterior margin of the eye disc continue to express Hth (Baonza and Freeman, 2002; Bessa et al., 2002; Lee and Treisman, 2001). Thus, dpp-mediated reduction of $\mathrm{H}$ th is essential for the progression of cells from Zone I (specified) to Zone II (determined) fates. Individual smo or tkvmutant clones, immediately posterior to the $M F$, retain $\mathrm{H}$ expression and display a delayed progression into Zone III states, while smo tkv double mutant clones completely lack H expression (Greenwood and Struhl, 1999). Furthermore, smoor madclones in Zone III continue to express Ey and ectopic dppexpression in Zone I non-autonomously blocks Ey expression (Bessa et al., 2002; Lee and Treisman, 2001). Taken together, these results suggest that the transition from Zone I to Zone II/ PPD is primarily dependent on low levels of $d p p$ signaling, while the transition from Zone II/PPD to Zone III (differentiated) requires both $h$ hand high levels of $d p p$ signaling.

\section{Wingless is a negative regulator of photoreceptor morphogenesis}

wingless $(w g)$ is a Drosophila ortholog of the vertebrate wnt family of growth factors (reviewed in Moon et al., 2002). wg is expressed anterior to the MF at the dorsal and ventral margins of the eye disc and is excluded from regions of the eye field that express Eya and so (Baonza and Freeman, 2002; Royet and Finkelstein, 1997). In the eye, wg acts as a negative regulator of MF initiation, preventing inappropriate retinal specification. (Baonza and Freeman, 2002; Ma and Moses, 1995; Treisman and Rubin, 1995). Loss-of-function clones of $D$-axin or zeste white 3 (zW3), which encode proteins that negatively regulate $w g$ signaling, mimic ectopic $w g$ pathway activation and block photoreceptor differentiation (Baonza and Freeman, 2002; Royet and Finkelstein, 1997). $D$-axinclones that lie posterior to the MF furrow continue to express Ey, Hth, and Tsh but lack Eya, So, and Dac. These results suggest that $w g$ signaling negatively regulates expression of Zone II/PPD genes that are not normally expressed in Zone I (Baonza and Freeman, 2002; Lee and Treisman, 2001). Cells mutant for frizzled 1 and frizzled 2 ( $f z 1$ and $f z 2$ ), which encode receptors for $w g$ signaling, are unable to respond to $w g . f z 1 f z 2$ double mutant cells in the anterior-most regions of the eye field ectopically express Eya and Dac, suggesting that wg normally cooperates with ey, hth, and tsh to prevent premature expression of Eya and Dac (Baonza and Freeman, 2002). Taken together, these results suggest that $w g$ signaling confers Zone I identity and prevents retinal determination by suppressing genes that are first expressed in Zone II/PPD.

\section{wg and dpp function antagonistically during eye development}

Cells at the posterior margin of the eye disc that are unable to transduce the dppsignal due to loss of puntor madfunction do not initiate photoreceptor differentiation. These mutant cells also upregulate the expression of $w g$, suggesting that $d p p$ is required for the downregulation of $w g$ during normal eye development (Hazelett et al., 1998; Wiersdorff et al., 1996). Furthermore, loss of $w g$ in the eye leads to ectopic MF initiation and dppexpression in anterior regions of the eye disc (Ma and Moses, 1995; Treisman and Rubin, 1995). Moreover, this ectopic MF initiation is blocked in eye discs that are simultaneously mutant for hhor dppand loss of $w g$ can dominantly suppress an eye specific loss-of-function mutant of $d p p$ (Treisman and Rubin, 1995). These results support a model in which $w g$ and $d p p$ function antagonistically in the eye disc. $w g$ acts negatively in Zone I to prevent premature MF initiation anteriorly. This ensures that only older Zone I cells respond to $d p p$, thereby converting these cells into a Zone II state.

\section{hh, dpp, and wg signaling define distinct zones of selector complex action}

Cells far anterior to the MF in Zone I, are not exposed to Dpp or Hh, express $e y, h t h$, and tsh and continue to proliferate. This proliferative, Zone I state is further maintained by $\mathrm{wg}$, which prevents Eya, So, and Dac expression and positively regulates $e y, h$ th and tsh expression. Cells immediately anterior to the MF in Zone II are exposed to Dpp signaling and respond by downregulating $\mathrm{Hth}$ and $\mathrm{Wg}$, and upregulating Eya, So, and Dac. In addition, these cells express the HLH proteins $\mathrm{H}$ and Emc, which in turn prevent atoexpression. Cells in Zone III are exposed to high levels of $\mathrm{Hh}$ and $\mathrm{Dpp}$ signaling and respond by downregulating Ey and Tsh, but continue to express Eya, So, and Dac. Cells in Zone III also downregulate $\mathrm{H}$ and Emc expression, upregulate expression of the proneural gene ato and begin selection of the first differentiated cell type in the ommatidium, the $\mathrm{R} 8$ photoreceptor. Thus, a major role of $\mathrm{Hh}$ and Dpp is to cause undifferentiated cells to refine their selector profiles and proceed toward determination and differentiation.

\section{Notch acts in concert with Dpp signaling to promote transition of cells from Zone II/PPD to Zone III}

Notch signaling plays important roles throughout development of the eye imaginal disc (Baker and Zitron, 1995). However, the precise role of $\mathrm{N}$ during the initiation of photoreceptor morphogenesis is controversial. One report suggested that blocking Notch signaling transforms the eye to an antenna, implying that $\mathrm{N}$ acts upstream of the eye specification genes (Kumar and Moses, 2001a). However, another report contradicts these findings. Specifically, loss-of-function clones of $N$ delay photoreceptor differentiation, but did not affect the expression of the eye selectors Ey, Eya, and Dac (Kenyon et al., 2003). 
Moreover, $N$ mutant clones posterior to the MF express elevated levels of Ey, suggesting that these cells remain in a Zone II/PPD state. These results suggest that $N$ does not act genetically upstream of the eye selector genes. Similarly, when" $N$ function is removed in the early $1^{\text {st }}$ instar eye disc using a temperature sensitive allele of $N$, cell number is reduced, but the expression of Ey and Eya is not lost (Kenyon et al., 2003). In addition, blocking $\mathrm{N}$ activation using a dominant negative form of $\mathrm{N}$ or its ligand Serrate (Ser) leads to an increase in the antennal field at the expense of the eye field, occasionally producing two antennae. These results support a model in which $N$ primarily regulates proliferation of undifferentiated precursor cells, but is not a major determinant of antennal or eye fate (Kenyon et al., 2003).

Misexpression of the $\mathrm{N}$ ligand Delta (DI) immediately anterior to the MF causes premature ato expression and photoreceptor differentiation. However, clones of D/expressing cells in the most anterior regions of the eye field (Zone I) do not induce photoreceptor differentiation. These results suggest that Notch requires additional signals to induce photoreceptor differentiation (Baonza and Freeman, 2001). Indeed, coexpression of $d p p$ and $D /$ is sufficient to induce photoreceptor differentiation anywhere anterior to the MF. These results suggest that Dpp and N signaling cooperate to induce the transition of cells from Zone II/PPD to Zone III (Baonza and Freeman, 2001). Furthermore, Nor D/mutant clones posterior to the MF maintain $\mathrm{H}$ expression, further suggesting that these

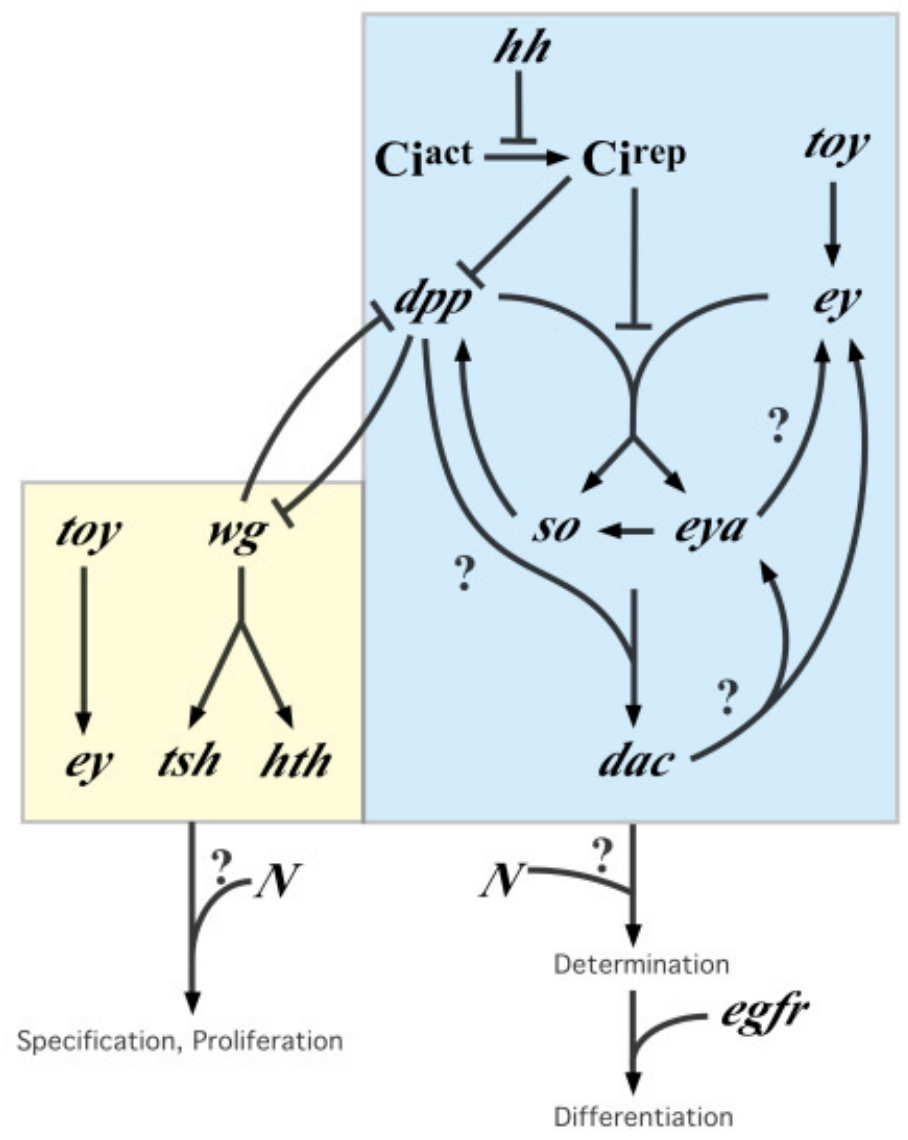

Fig. 3. An integrated model for the initiation of photoreceptor morphogenesis. See text for details. cells fail to transition from Zone II/PPD to Zone III (Baonza and Freeman, 2001). Thus, $\mathrm{N}$ signaling does not appear to play a major role in the regulation of core eye selector genes. Instead, N signaling is primarily involved in down-regulating $h$ and emc expression, thereby allowing ato expression and facilitating the Zone II to Zone III transition.

\section{egfr signaling facilitates the transition from determined to differentiated cell fates}

A temperature sensitive mutant of the egfr grown at the restrictive temperature prior to initiation of the MF blocks furrow initiation. However, adult eyes obtained from the same experiment lack all differentiated cell types except the interommatidial bristles (Kumar and Moses, 2001b). Furthermore, posterior margin clones of egfrin the eye disc cause impaired cell growth and excess cell death (Dominguez et al., 1998). Finally, although egfrsignaling is not required for the selection of the founder $\mathrm{R} 8$ photoreceptor, loss of egfr prevents the subsequent differentiation of all other photoreceptors (Freeman, 1997; Yang and Baker, 2001). Taken together, these results suggest that egfrsignaling is essential for proper differentiation of specific cell types during development of the eye disc. However, the exact role of egfrsignaling in regulating selector gene expression during retinal specification and determination remains unclear and requires additional investigation.

\section{An integrated model for retinal morphogenesis}

The overall development of the Drosophila eye disc can be categorized as a three step process involving specification, determination, and differentiation. Each stage is associated with distinct selector complexes that are modulated by different extracellular inputs. Specification occurs in Zone I during a predominantly proliferative state and is primarily controlled by the Pax6 homologs toy and ey. In addition, wg signaling positively regulates $h$ thand $t$ shexpression, which encode proteins that can complex with Ey to regulate proliferation of the eye-antennal disc cells. Expression and diffusion of Dpp anteriorly from the MF converts cells exiting Zone I into a determined, Zone II state (Figs. 2,3). Thus, Zone II cells initiate the expression of eya,so and dac and downregulate the expression of $h$ th and $e x d$, creating a new selector environment. The creation of a determined tissue is followed by the differentiation of the founder $R 8$ cell and recruitment of other cell types in Zones III and IV. In Zone III additional inputs from the $h h$, Nand egfrsignaling pathways drive expression of the proneural gene ato and down regulate toy, ey, and tsh, eventually leading to differentiation of the founder R8 photoreceptor and recruitment of all other cell types.

\section{Conclusions and perspectives}

Over the last decade, our understanding of the early events required for retinal specification and determination in the developing Drosophila eye has improved dramatically. However, what we have learned so far is dwarfed by what remains to be discovered. The lack of well-defined targets of the eye selector complexes presents the most significant gap in our understanding of how the gradual progression from specification to determination and finally to differentiation occurs in the eye field. It is estimated that more than three thousand genes are required to construct the adult 
Drosophilaeye (Thaker and Kankel, 1992). New troves of genome sequencing data have allowed whole genome analyses of developmental programs. However, only two studies reported so far have used in silico techniques to discover target genes activated during different phases of Drosophilaeye development. In the first study, misexpression of ey in the leg, followed by microarray analysis, was used to identify downstream targets of the retinal specification program (Michaut et al., 2003). This approach uncovered at least 371 genes that are upregulated by eyduring eye specification. The second study utilized fluorescent activated cell sorting followed by serial analysis of gene expression (SAGE) to discover genes that were specifically upregulated anterior to, within, or behind the MF (Jasper et al., 2002). 372 genes were found to show significant changes in expression. These studies uncover a global genomic switch that occurs when proliferating undifferentiated cells commit to differentiation as retinal tissue. In addition, in situhybridization analyses of several candidate genes in both studies were indeed indicative of domainspecific expression, and perhaps function, in the eye. These studies are the first, among what we expect will be many, to use high throughput genomics to delve deeper into understanding the complexities of eye specification, determination, and differentiation.

Arguably the most fascinating discovery of all is that genetic networks involved in Drosophila eye development are conserved across phylogeny. Indeed, vertebrate Pax 6 orthologs are necessary and sufficient for eye development and orthologs of other RD genes play import roles during vertebrate retinal development (Hanson, 2001). Surprisingly, the discovery that vertebrate myogenesis utilizes Pax3, Eya2, Six1, and Dach2, vertebrate homologs of Drosophila RD genes, suggest that entire genetic networks can be co-opted to regulate distinct developmental pathways (Heanue et al., 1999). However, it has also become apparent that there is evolutionary divergence and not all genes and pathways are functionally conserved across phylogeny. A prime example is the discovery that the Drosophila ortholog of the vertebrate retinal homeobox gene $R x, d r x$, is not required for eye development (Davis etal., 2003). Mouse knockouts of the $R x$ gene, however, develop with no eyes and $R x$ functions upstream of Pax6during vertebrate eye specification (Mathers et al., 1997). Thus, there is considerable variation across species in the genetic foundations of eye specification, with many similarities and yet significant differences. The immense power of genetic manipulation and the advent of powerful genomic tools have made Drosophila an invaluable model system to decipher the complexities of eye specification. We expect the pace of new discoveries, particularly those aided by enhanced genomic tools, to accelerate rapidly.

\section{Acknowledgements}

We would like to thank Benjamin Frankfort for critical reading of this manuscriptand helpfuldiscussions. Research in the laboratory is supported by the National Eye Institute and the Retina Research Foundation.

\section{References}

BAKER, N. E., and ZITRON, A. E. (1995). Drosophila eye development: Notch and Delta amplify a neurogenic pattern conferred on the morphogenetic furrow by scabrous. Mech. Dev. 49: 173-189.

BAONZA, A., and FREEMAN, M. (2001). Notch signalling and the initiation of neural development in the Drosophila eye. Development 128: 3889-3898.
BAONZA, A., and FREEMAN, M. (2002). Control of Drosophila eye specification by Wingless signalling. Development 129: 5313-5322.

BASLER, K., and STRUHL, G. (1994). Compartment boundaries and the control of Drosophila limb pattern by hedgehog protein. Nature 368: 208-214.

BESSA, J., GEBELEIN, B., PICHAUD, F., CASARES, F., and MANN, R. S. (2002). Combinatorial control of Drosophila eye development by eyeless, homothorax, and teashirt. Genes. Dev. 16: 2415-2427.

BONINI, N. M., BUI, Q. T., GRAY-BOARD, G. L., and WARRICK, J. M. (1997). The Drosophila eyes absent gene directs ectopic eye formation in a pathway conserved between flies and vertebrates. Development 124: 4819-4826.

BONINI, N. M., LEISERSON, W. M., and BENZER, S. (1993). The eyes absent gene: genetic control of cell survival and differentiation in the developing Drosophila eye. Cel/72: 379-395.

BOROD, E. R., and HEBERLEIN, U. (1998). Mutual regulation of decapentaplegic and hedgehog during the initiation of differentiation in the Drosophila retina. Dev. Biol. 197: 187-197

BROWN, N. L., SATTLER, C. A., MARKEY, D. R., and CARROLL, S. B. (1991). hairy gene function in the Drosophila eye: normal expression is dispensable but ectopic expression alters cell fates. Development 113: 1245-1256.

BROWN, N. L., SATTLER, C. A., PADDOCK, S. W., and CARROLL, S. B. (1995). Hairy and emc negatively regulate morphogenetic furrow progression in the Drosophila eye. Cel/80: 879-887.

BUI, Q. T., ZIMMERMAN, J. E., LIU, H., GRAY-BOARD, G. L., and BONINI, N. M. (2000). Functional analysis of an eye enhancer of the Drosophila eyes absent gene: differential regulation by eye specification genes. Dev. Biol.221:355-364.

BURKE, R., and BASLER, K. (1996). Hedgehog-dependent patterning in the Drosophila eye can occur in the absence of Dpp signaling. Dev. Biol. 179: 360368.

CHANUT, F., and HEBERLEIN, U. (1997). Role of decapentaplegic in initiation and progression of the morphogenetic furrow in the developing Drosophila retina. Development 124: 559-567.

CHEN, R., AMOUI, M., ZHANG, Z., and MARDON, G. (1997). Dachshund and eyes absent proteins form a complex and function synergistically to induce ectopic eye development in Drosophila. Cel/91: 893-903.

CHEN, R., HALDER, G., ZHANG, Z., and MARDON, G. (1999). Signaling by the TGF-beta homolog decapentaplegic functions reiteratively within the network of genes controlling retinal cell fate determination in Drosophila. Development 126: $935-943$.

CHEYETTE, B. N., GREEN, P. J., MARTIN, K., GARREN, H., HARTENSTEIN, V. and ZIPURSKY, S. L. (1994). The Drosophila sine oculis locus encodes a homeodomain-containing protein required for the development of the entire visual system. Neuron 12: 977-996.

CHOW, R. L., ALTMANN, C. R., LANG, R. A., and HEMMATI-BRIVANLOU, A. (1999). Pax6 induces ectopic eyes in a vertebrate. Development 126: 42134222.

CURTISS, J., and MLODZIK, M. (2000). Morphogenetic furrow initiation and progression during eye development in Drosophila: the roles of decapentaplegic, hedgehog and eyes absent. Development 127: 1325-1336.

CZERNY, T., HALDER, G., KLOTER, U., SOUABNI, A., GEHRING, W. J., and BUSSLINGER, M. (1999). twin of eyeless, a second Pax-6 gene of Drosophila, acts upstream of eyeless in the control of eye development. Mol. Cel/3: 297307.

DAVIS, R. J., SHEN, W., HEANUE, T. A., and MARDON, G. (1999). Mouse Dach, a homologue of Drosophila dachshund, is expressed in the developing retina, brain and limbs. Dev. Genes. Evol. 209: 526-536.

DAVIS, R. J., TAVSANLI, B. C., DITTRICH, C., WALLDORF, U., and MARDON, G. (2003). Drosophila retinal homeobox (drx) is not required for establishment of the visual system, but is required for brain and clypeus development. Dev. Biol. 259: $272-287$.

DOMINGUEZ, M., and HAFEN, E. (1997). Hedgehog directly controls initiation and propagation of retinal differentiation in the Drosophila eye. Genes. Dev. 11: 3254-3264.

DOMINGUEZ, M., WASSERMAN, J. D., and FREEMAN, M. (1998). Multiple functions of the EGF receptor in Drosophila eye development. Curr. Biol. 8 : 1039-1048. 
FASANO, L., RODER, L., CORE, N., ALEXANDRE, E., VOLA, C., JACQ, B., and KERRIDGE, S. (1991). The gene teashirt is required for the development of Drosophila embryonic trunk segments and encodes a protein with widely spaced zinc finger motifs. Cel/64: 63-79.

FRANKFORT, B. J., and MARDON, G. (2002). R8 development in the Drosophila eye: a paradigm for neural selection and differentiation. ÄDevelopment 129 : 1295-1306.

FREEMAN, M. (1994). The spitz gene is required for photoreceptor determination in the Drosophila eye where it interacts with the EGF receptor. Mech. Dev. 48: 25-33.

FREEMAN, M. (1997). Cell determination strategies in the Drosophila eye. Development 124: 261-270.

FREEMAN, M., and GURDON, J. B. (2002). Regulatory principles of developmental signaling. Annu. Rev. Cell Dev. Biol. 18: 515-539.

FU, W., and BAKER, N. E. (2003). Deciphering synergistic and redundant roles of Hedgehog, Decapentaplegic and Delta that drive the wave of differentiation in Drosophila eye development. Development 130: 5229-5239.

GARCIA-BELLIDO, A., and MERRIAM, J. R. (1969). Cell lineage of the imaginal discs in Drosophila gynandromorphs. J. Exp. Zool. 170: 61-75.

GARCIA-BELLIDO, A., RIPOLL, P., and MORATA, G. (1973). Developmental compartmentalisation of the wing disk of Drosophila. Nat. New. Biol. 245: 251253.

GLASER, T., WALTON, D. S., and MAAS, R. L. (1992). Genomic structure, evolutionary conservation and aniridia mutations in the human PAX6 gene. Nat. Genet. 2: 232-239.

GONZALEZ-CRESPO, S., and MORATA, G. (1995). Control of Drosophila adult pattern by extradenticle. Development 121: 2117-2125.

GREENWOOD, S., and STRUHL, G. (1999). Progression of the morphogenetic furrow in the Drosophila eye: the roles of Hedgehog, Decapentaplegic and the Raf pathway. Development 126: 5795-5808.

HALDER, G., CALLAERTS, P., FLISTER, S., WALLDORF, U., KLOTER, U., and GEHRING, W. J. (1998). Eyeless initiates the expression of both sine oculis and eyes absent during Drosophila compound eye development. Development 125: 2181-2191

HALDER, G., CALLAERTS, P., and GEHRING, W. J. (1995). Induction of ectopic eyes by targeted expression of the eyeless gene in Drosophila. Science 267: 1788-1792.

HANSON, I. M. (2001). Mammalian homologues of the Drosophila eye specification genes. Semin. Cell Dev. Biol. 12: 475-484.

HAYNIE, J. L., and BRYANT, P. J. (1986). Development of the eye-antenna imaginal disc and morphogenesis of the adult head in Drosophila melanogaster. J. Exp. Zool. 237: 293-308.

HAZELETT, D. J., BOUROUIS, M., WALLDORF, U., and TREISMAN, J. E. (1998). decapentaplegic and wingless are regulated by eyes absent and eyegone and interact to direct the pattern of retinal differentiation in the eye disc. Development 125: 3741-3751.

HEANUE, T. A., RESHEF, R., DAVIS, R. J., MARDON, G., OLIVER, G., TOMAREV S., LASSAR, A. B., and TABIN, C. J. (1999). Synergistic regulation of vertebrate muscle development by Dach2, Eya2, and Six1, homologs of genes required for Drosophila eye formation. Genes. Dev. 13: 3231-3243.

HEBERLEIN, U., SINGH, C. M., LUK, A. Y., and DONOHOE, T. J. (1995). Growth and differentiation in the Drosophila eye coordinated by hedgehog. Nature 373: 709-711.

HEBERLEIN, U., WOLFF, T., and RUBIN, G. M. (1993). The TGF beta homolog dpp and the segment polarity gene hedgehog are required for propagation of a morphogenetic wave in the Drosophila retina. Cel/75: 913-926.

HILL, R. E., FAVOR, J., HOGAN, B. L., TON, C. C., SAUNDERS, G. F., HANSON, I. M., PROSSER, J., JORDAN, T., HASTIE, N. D., and VAN HEYNINGEN, V. (1991). Mouse small eye results from mutations in a paired-like homeoboxcontaining gene. Nature 354: 522-525.

HOGE, M. A. (1915). Another gene in the fourth chromosome of Drosophila. American Naturalist 49: 47-49.

HSIAO, F. C., WILLIAMS, A., DAVIES, E. L., and REBAY, I. (2001). Eyes absent mediates cross-talk between retinal determination genes and the receptor tyrosine kinase signaling pathway. Dev. Cel/1: 51-61.
INGHAM, P. W., and MCMAHON, A. P. (2001). Hedgehog signaling in animal development: paradigms and principles. Genes. Dev. 15: 3059-3087.

JANG, C. C., CHAO, J. L., JONES, N., YAO, L. C., BESSARAB, D. A., KUO, Y. M., JUN, S., DESPLAN, C., BECKENDORF, S. K., and SUN, Y. H. (2003). Two Pax genes, eye gone and eyeless, act cooperatively in promoting Drosophila eye development. Development 130: 2939-2951.

JARMAN, A. P., GRELL, E. H., ACKERMAN, L., JAN, L. Y., and JAN, Y. N. (1994). Atonal is the proneural gene for Drosophila photoreceptors. Nature 369: 398400 .

JASPER, H., BENES, V., ATZBERGER, A., SAUER, S., ANSORGE, W., and BOHMANN, D. (2002). A genomic switch at the transition from cell proliferation to terminal differentiation in the Drosophila eye. Dev. Cel/3: 511-521.

JORDAN, T., HANSON, I., ZALETAYEV, D., HODGSON, S., PROSSER, J., SEAWRIGHT, A., HASTIE, N., and VAN HEYNINGEN, V. (1992). The human PAX6 gene is mutated in two patients with aniridia. Nat. Genet. 1: 328-332.

KAMMERMEIER, L., LEEMANS, R., HIRTH, F., FLISTER, S., WENGER, U., WALLDORF, U., GEHRING, W. J., and REICHERT, H. (2001). Differential expression and function of the Drosophila Pax6 genes eyeless and twin of eyeless in embryonic central nervous system development. Mech. Dev. 103: 71-78.

KAWAKAMI, K., SATO, S., OZAKI, H., and IKEDA, K. (2000). Six family genes structure and function as transcription factors and their roles in development. Bioessays 22: 616-626.

KENYON, K. L., RANADE, S. S., CURTISS, J., MLODZIK, M., and PIGNONI, F. (2003). Coordinating proliferation and tissue specification to promote regional identity in the Drosophila head. Dev. Cel/5: 403-414

KIM, S. S., ZHANG, R. G., BRAUNSTEIN, S. E., JOACHIMIAK, A., CVEKL, A., and HEGDE, R. S. (2002). Structure of the retinal determination protein Dachshund reveals a DNA binding motif. Structure (Camb) 10: 787-795

KOZMIK, Z., PFEFFER, P., KRALOVA, J., PACES, J., PACES, V., KALOUSOVA A., and CVEKL, A. (1999). Molecular cloning and expression of the human and mouse homologues of the Drosophila dachshund gene. Dev. Genes. Evol. 209: 537-545.

KRONHAMN, J., FREI, E., DAUBE, M., JIAO, R., SHI, Y., NOLL, M., and RASMUSON-LESTANDER, A. (2002). Headless flies produced by mutations in the paralogous Pax6 genes eyeless and twin of eyeless. Development 129: 1015-1026.

KUMAR, J. P., and MOSES, K. (2001a). EGF receptor and Notch signaling act upstream of Eyeless/Pax6 to control eye specification. Cel/104: 687-697.

KUMAR, J. P., and MOSES, K. (2001b). The EGF receptor and notch signaling pathways control the initiation of the morphogenetic furrow during Drosophila eye development. Development 128: 2689-2697.

LEE, J. D., and TREISMAN, J. E. (2001). The role of Wingless signaling in establishing the anteroposterior and dorsoventral axes of the eye disc. Development 128: 1519-1529.

LEE, J. J., VON KESSLER, D. P., PARKS, S., and BEACHY, P. A. (1992). Secretion and localized transcription suggest a role in positional signaling for products of the segmentation gene hedgehog. Ce//71: 33-50.

MA, C., and MOSES, K. (1995). Wingless and patched are negative regulators of the morphogenetic furrow and can affect tissue polarity in the developing Drosophila compound eye. Development 121: 2279-2289.

MA, C., ZHOU, Y., BEACHY, P. A., and MOSES, K. (1993). The segment polarity gene hedgehog is required for progression of the morphogenetic furrow in the developing Drosophila eye. Cel/75: 927-938

MANN, R. S., and MORATA, G. (2000). The developmental and molecular biology of genes that subdivide the body of Drosophila. Annu. Rev. Cell Dev. Biol. 16: 243-271.

MARDON, G., SOLOMON, N. M., and RUBIN, G. M. (1994). dachshund encodes a nuclear protein required for normal eye and leg development in Drosophila. Development 120: 3473-3486

MASUCCI, J. D., MILTENBERGER, R. J., and HOFFMANN, F. M. (1990). Patternspecific expression of the Drosophila decapentaplegic gene in imaginal disks is regulated by 3' cis-regulatory elements. Genes. Dev. 4: 2011-2023.

MATHERS, P. H., GRINBERG, A., MAHON, K. A., and JAMRICH, M. (1997). The $\mathrm{Rx}$ homeobox gene is essential for vertebrate eye development. Nature 387: 603-607. 
METHOT, N., and BASLER, K. (1999). Hedgehog controls limb development by regulating the activities of distinct transcriptional activator and repressor forms of Cubitus interruptus. Cel/96: 819-831.

MICHAUT, L., FLISTER, S., NEEB, M., WHITE, K. P., CERTA, U., and GEHRING, W. J. (2003). Analysis of the eye developmental pathway in Drosophila using DNA microarrays. Proc. Natl. Acad. Sci. USA. 100: 4024-4029.

MOON, R. T., BOWERMAN, B., BOUTROS, M., and PERRIMON, N. (2002). The promise and perils of Wnt signaling through beta-catenin. Science296: 1644-1646.

NEUMANN, C., and COHEN, S. (1997). Morphogens and pattern formation. Bioessays 19: 721-729.

NIIMI, T., SEIMIYA, M., KLOTER, U., FLISTER, S., and GEHRING, W. J. (1999). Direct regulatory interaction of the eyeless protein with an eye-specific enhancer in the sine oculis gene during eye induction in Drosophila. Development 126: 2253-2260.

PAI, C. Y., KUO, T. S., JAW, T. J., KURANT, E., CHEN, C. T., BESSARAB, D. A., SALZBERG, A., and SUN, Y. H. (1998). The Homothorax homeoprotein activates the nuclear localization of another homeoprotein, extradenticle, and suppresses eye development in Drosophila. Genes. Dev. 12: 435-446.

PAN, D., and RUBIN, G. M. (1995). cAMP-dependent protein kinase and hedgehog act antagonistically in regulating decapentaplegic transcription in Drosophila imaginal discs. Cel/80: 543-552.

PAN, D., and RUBIN, G. M. (1998). Targeted expression of teashirt induces ectopic eyes in Drosophila. Proc. Natl. Acad. Sci. USA. 95: 15508-15512.

PAPPU, K. S., CHEN, R., MIDDLEBROOKS, B. W., WOO, C., HEBERLEIN, U., and MARDON, G. (2003). Mechanism of hedgehog signaling during Drosophila eye development. Development 130: 3053-3062.

PIGNONI, F., HU, B., ZAVITZ, K. H., XIAO, J., GARRITY, P. A., and ZIPURSKY, S. L. (1997). The eye-specification proteins So and Eya form a complex and regulate multiple steps in Drosophila eye development. Ce//91: 881-891.

PIGNONI, F., and ZIPURSKY, S. L. (1997). Induction of Drosophila eye development by decapentaplegic. Development 124: 271-278.

PUNZO, C., KURATA, S., and GEHRING, W. J. (2001). The eyeless homeodomain is dispensable for eye development in Drosophila. Genes. Dev. 15: 1716-1723.

PUNZO, C., SEIMIYA, M., FLISTER, S., GEHRING, W. J., and PLAZA, S. (2002). Differential interactions of eyeless and twin of eyeless with the sine oculis enhancer. Development 129: 625-634.

QUIRING, R., WALLDORF, U., KLOTER, U., and GEHRING, W. J. (1994) Homology of the eyeless gene of Drosophila to the Small eye gene in mice and Aniridia in humans. Science 265: 785-789.

RAFTERY, L. A., and SUTHERLAND, D. J. (1999). TGF-beta family signal transduction in Drosophila development: from Mad to Smads. Dev. Biol. 210: 251-268.

RAYAPUREDDI, J. P., KATTAMURI, C., STEINMETZ, B. D., FRANKFORT, B. J., OSTRIN, E. J., MARDON, G., and HEGDE, R. S. (2003). Eyes Absent represents a class of protein tyrosine phosphatases. Nature 426: 295-298.

READY, D. F., HANSON, T. E., and BENZER, S. (1976). Development of the Drosophila retina, a neurocrystalline lattice. Dev. Biol. 53: 217-240.

RIECKHOF, G. E., CASARES, F., RYOO, H. D., ABU-SHAAR, M., and MANN, R. S. (1997). Nuclear translocation of extradenticle requires homothorax, which encodes an extradenticle-related homeodomain protein. Cel/91: 171-183.

ROYET, J., and FINKELSTEIN, R. (1997). Establishing primordia in the Drosophila eye-antennal imaginal disc: the roles of decapentaplegic, wingless and hedgehog. Development 124: 4793-4800.

SEIMIYA, M., and GEHRING, W. J. (2000). The Drosophila homeobox gene optix is capable of inducing ectopic eyes by an eyeless-independent mechanism. Development 127: 1879-1886.

SEO, H. C., CURTISS, J., MLODZIK, M., and FJOSE, A. (1999). Six class homeobox genes in drosophila belong to three distinct families and are involved in head development. Mech. Dev. 83: 127-139.
SHEN, W., and MARDON, G. (1997). Ectopic eye development in Drosophila induced by directed dachshund expression. Development 124: 45-52.

SILVER, S. J., DAVIES, E. L., DOYON, L., and REBAY, I. (2003). Functional dissection of eyes absent reveals new modes of regulation within the retinal determination gene network. Mol. Cell Biol. 23: 5989-5999.

SINGH, A., KANGO-SINGH, M., and SUN, Y. H. (2002). Eye suppression, a novel function of teashirt, requires Wingless signaling. Development 129: 4271-4280.

SPENCER, F. A., HOFFMANN, F. M., and GELBART, W. M. (1982). Decapentaplegic: a gene complex affecting morphogenesis in Drosophila melanogaster. Ce//28: 451-461.

STRUTT, D. I., and MLODZIK, M. (1995). Ommatidial polarity in the Drosophila eye is determined by the direction of furrow progression and local interactions. Development 121: 4247-4256.

STRUTT, D. I., and MLODZIK, M. (1997). Hedgehog is an indirect regulator of morphogenetic furrow progression in the Drosophila eye disc. Development 124: 3233-3240.

TAVSANLI, B. C., OSTRIN, E. J., BURGESS, H. K., MIDDLEBROOKS, B. W., PHAM, T.A. and MARDON, G. (2004). Structure-function analysis of the Drosophila retinal determination protein Dachshund. Dev Bio/272: 231-47.

THAKER, H. M., and KANKEL, D. R. (1992). Mosaic analysis gives an estimate of the extent of genomic involvement in the development of the visual system in Drosophila melanogaster. Genetics 131: 883-894.

TIO, M., MA, C., and MOSES, K. (1994). spitz, a Drosophila homolog of transforming growth factor-alpha, is required in the founding photoreceptor cells of the compound eye facets. Mech. Dev. 48: 13-23.

TIO, M., and MOSES, K. (1997). The Drosophila TGF alpha homolog Spitz acts in photoreceptor recruitment in the developing retina. Development 124:343-351.

TOOTLE, T. L., SILVER, S. J., DAVIES, E. L., NEWMAN, V., LATEK, L. R., MILLS, I. A., SELENGUT, J. D., PARLIKAR, B. E. W., and REBAY, I. (2003). The transcription factor Eyes Absentis is a protein tyrosine phosphatases. Nature 426: $299-302$

TREISMAN, J. E., and RUBIN, G. M. (1995). wingless inhibits morphogenetic furrow movement in the Drosophila eye disc. Development 121: 3519-3527.

VAN DOREN, M., ELLIS, H. M., and POSAKONY, J. W. (1991). The Drosophila extramacrochaetae protein antagonizes sequence-specific DNA binding by daughterless/achaete-scute protein complexes. Development 113: 245-255.

WIERSDORFF, V., LECUIT, T., COHEN, S. M., and MLODZIK, M. (1996). Mad acts downstream of Dpp receptors, revealing a differential requirement for dpp signaling in initiation and propagation of morphogenesis in the Drosophila eye. Development 122: 2153-2162.

WILSON, D., SHENG, G., LECUIT, T., DOSTATNI, N., and DESPLAN, C. (1993). Cooperative dimerization of paired class homeo domains on DNA. Genes. Dev. 7: $2120-2134$

WOLFF, T., and READY, D. F. (1991). The beginning of pattern formation in the Drosophila compound eye: the morphogenetic furrow and the second mitotic wave. Development 113: 841-850.

WOLFF, T., and READY, D. F. (1993). Pattern Formation in the Drosophila retina. In The Development of Drosophila melanogaster, M. Bate, and A. Martinez Arias, eds. (Plainview, N.Y., Cold Spring Harbor Laboratory Press), pp. 2 v. (x, 1558)

XU, W., ROULD, M. A., JUN, S., DESPLAN, C., and PABO, C. O. (1995). Crystal structure of a paired domain-DNA complex at 2.5 A resolution reveals structural basis for Pax developmental mutations. Cel/80: 639-650.

YANG, L., and BAKER, N. E. (2001). Role of the EGFR/Ras/Raf pathway in specification of photoreceptor cells in the Drosophila retina. Development 128 : 1183-1191.

ZIMMERMAN, J. E., BUI, Q. T., LIU, H., and BONINI, N. M. (2000). Molecular genetic analysis of Drosophila eyes absent mutants reveals an eye enhancer element. Genetics 154: 237-246. 